\title{
CONCERNING SOME HYDROMETRA FROM AFRICA (HEMIPTERA) ${ }^{1}$
}

\author{
BY H. B. HUNGERFORD \\ University of Kansas
}

In the Annales Musei Nationalis Hungarici, Vol. XXVIII, 1934, there appeared an article entitled "The Hydrometridae of the Hungarian National Museum and other studies in the Family" by Hungerford and Evans. This paper contains drawings of most of the known species and keys for the separation of all of the species of the world known to the authors. Twenty-five of the sixty-six Hydrometra treated are described as new. Unfortunately there occurred a lapse of several years between the completion of the manuscript and its publication and in the interim three papers describing new Hydrometra appeared. However, only $H$. ugandae Jaczewski is from Africa. Since 1934 six more African species have been described, five of them by Poisson and one by Hoberlandt, and some specimens have been received by me for study, including two undescribed species.

I am indebted to my friends Dr. J. C. Bradley and Dr. F. X. Williams for the opportunity to study the Hydrometra taken by them during their recent trips in Africa. Dr. Bradley's material was sent to Cornell where Henry Dietrich was kind enough to forward it to me. Dr. Williams' material was promptly forwarded by Dr. Bequaert from the Museum of Comparative Zoology at Harvard and we have mounted and labeled this material to avoid any delay in its study.

In the material collected by Dr. J. C. Bradley are the following:

Hydrometra albolineolata Reuter

Tonga, Sudan, Oct. 28, 1948, White Nile, lat. $9^{\circ}-28^{\prime}$ N., long. $31^{\circ}-2^{\prime}$, J. C. Bradley, 1 ô, 3 ㅇ (Cornell); 1 of, 1 ㅇ (F. H. Snow Coll.).

${ }^{1}$ Published with a grant from the Museum of Comparative Zoology at Harvard College. 
Malakal, Sudan, Oct. 27, 1948, J. C. Bradley, 1 oิ, 3 우 (Cornell).

Steamer on White Nile, Sudan, Oct. 26,1948 , lat. $10^{\circ}-45^{\prime} \mathrm{N}$ to $10^{\circ}-26^{\prime} \mathrm{N}$, J. C. Bradley, 1 \% (Cornell).

Bahr el Jebel, Sudan, Nov. 3, 1948, Terakeka to Mongalla to lat. $5^{\circ}-11^{\prime} \mathrm{N}$, J. C. Bradley, 1 \& (Cornell).

Hydrometra sp.

Bahr el Jebel, Sudan, Nov. 3, 1948, J. C. Bradley, Terakeka to Mongalla to lat. $5^{\circ}-11^{\prime}$ N. (1 ㅇ). (Not but near H. gracilenta Horv.)

Dr. F. X. Williams sent the following four species, one of which is new:

Hydrometra africana H. \& E.

Africa, Amani, Tanganyika Terr., Feb. 1948, F. X.

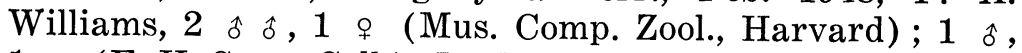
1 o (F. H. Snow Coll.). In these specimens the males have the large hair tufts on the sides of the first genital segment that were lacking in the type. The females have two hair tufts on rear margin of last dorsal abdominal segment that are partly effaced on the allotype but present on a paratype. Hydrometra ugandae Jaczewski

Africa, Uganda, Kichwamba, Feb. 28, 1948, F. .X. Williams, 1 ô (Mus. Comp. Zool., Harvard); 1 oे (F. H. Snow Coll.).

Hydrometra chopardi Poisson

Africa, Kenya Col., 28 miles N. of Nairobi, Thika River Falls, Feb. 20, 1948, F. X. Williams, 4 항, 6 우 (Mus. Comp. Zool., Harvard) ; 1 ô, 1 \& (F. H. Snow Coll.).

\section{Hydrometra poissoni $\mathrm{n}$. sp.}

Size and color: Length $9.24 \mathrm{~mm}$. to $9.54 \mathrm{~mm}$. (males). The general color is dark brown. The head nearly black with a faint longitudinal frosted line on the postocular space; the pronotum with a narrow longitudinal median frosted line bordered successively on each side by a dark, nearly black, purplish-brown band, a brown band, another dark purplish-brown band, outside of which is a frosted line; the hemelytra have two longitudinal white lines, one slender 
near the costal margin and the other a broader median band which arises from it near its base. Both bands are broken by the dark veins that cross them. There is a streak of white on the hemelytra paralleling the sides of the scutellum. Underside of body somewhat frosted, the sides of the abdomen with a nearly black subconnexival band broken at the segmental junction by frosted spots.

Structural characteristics:

Head: Length 93 units; the ratio of the anteocular part of the head to the postocular part is given by the formula AO : PO :: $57: 27$. The dorsal interocular groove less than the diameter of the eye. The clypeus is quadrate, medianly depressed and slightly emarginate in front, its median length about three fifths its width, the rostrum surpassing two thirds of the postocular distance. The antennal segments: $1: 2: 3: 4:: 18: 34: 77: \mathrm{X} . \dagger$

Pronotum: Length 46 units*; the pitting very faint, almost indiscernible, only the curved row of pits behind the anterior acetabulum plainly marked.

Coxae: The distance between the first and second coxae is to that between the seccnd and third as $34: 62$. The anterior acetabulum has a faint pit on each side of the cleft. The middle acetabulum with two faint pits on each side of the cleft; the posterior acetabulum is unpitted on the sides but faintly pitted above.

Femora: The anterior femora surpass the base of the antennal tubercles. The hind femora reach the tip of the abdomen.

Abdomen: The last abdominal segment and the first genital of the male without hair tufts or spines. The first genital segment ventro-laterally depressed, leaving a broad midventral longitudinal keel with some hairs on either side. Seen from above, the first genital segment is broadest about the middle; the terminal dorsal process is stout, slightly upturned and less than one third the length of the segment.

Comparative notes: This species is near H. smithi $\mathrm{H} \& \mathrm{E}$., described from Sierra Leone, but both the shape of the ter-

$\dagger$ last segment missing.

$*$ unit $=.033 \mathrm{~mm}$. 
minal segments of the males and the color patterns are different. $H$. smithi has a more slender genital segment as seen from above and parallel longitudinal white bands on the last abdominal and genital segments. These are lacking in $H$. poissoni.

Described from two males labeled "Africa, Uganda, 60 miles west of Kampala, March 4, 1948, F. X. Williams," Holotype in the Museum of Comparative Zoology (No. 28493) at Harvard, the paratype in the F. H. Snow Collection. Named in honor of Dr. Raymond Poisson who has described several Hydrometra from Africa.

\section{Hydrometra albolineolata Reuter}

While the Hungerford and Evans paper of 1934 was in press, Dr. Jaczewski published his "Notes on the Aquatic Heteroptera of the Ethiopian Region"' in which he redescribed $H$. albolineolata Reuter and described as new a species which he called Hydrometra ugandae.

His conception of Reuter's species was based upon a male specimen from "Addah, Guinea," loaned to him by Dr. Horvath of the Museum in Budapest and presumably a syntype. However, I had previously studied the entire series of specimens in Budapest, two syntypes in the Museum at Perth, Scotland, and one in the U. S. National Museum at Washington, D. C., and my conception of the species (which differs from that of Dr. Jaczewski) is given on page 50 and Plate II of our 1934 paper.

Being puzzled by the difference in concept concerning this species, I have studied the question again and reexamined material which forces me to conclude that my conception of Reuter's species is the correct one. I am therefore selecting a male syntype that corresponds to the figures on Plate II of the Annales Musei Nationalis Hungarici XXVIII, page 48 , as the lectoholotype.

I have examined a pair of specimens determined as $H$. albolineolata by Dr. Jaczewski and the male labeled "Zanzibar, H. J. Snell" runs to $H$. africana H. \& E. The female

\footnotetext{
2 Stylops, Vol. 1, Part 5, pp. 100-104, 1932.
} 
from "Uganda, Kampala, G. L. R. Hancock" is not quite the same.

\section{Hydrometra ugandae Jaczewski}

This species was described from Uganda: Bugomolo. The large brush of semi-erect brown hairs on the basal portion of the seventh abdominal tergite of the female and the short somewhat downward curving terminal spine makes the female readily distinguishable. I have examined the female paratype. Dr. China made a drawing of the male type in the British Museum and this drawing shows spiny tufts present on the last abdominal segment although Dr. Jaczewski's description says they are not present.

\section{Hydrometra goodi n. sp.}

Size and Color: Length $12.15 \mathrm{~mm}$. ( o ) - $12.96 \mathrm{~mm}$. ( $q$ ). General color brown, the abdominal tergites, except the last one, shining, nearly black and contrasting with the much lighter connexivum. The pronotum with a narrow longitudinal median frosted line bordered successively on each side by a purplish-brown band, a brown band, another purplish band, outside of which is a curved frosted line above the anterior acetabula and another bordering the margin of the posterior lobe and continuing to the posterior acetabula. Under side of body somewhat frosted. Above, the connexivum has a small frosted spot at the segmental junctions. The last abdominal segment and genital segment covered with short hairs in both sexes.

\section{Structural characteristics:}

Head: Length 140 units; the ratio of the anteocular part of the head to the postocular part is given by the formula AO : PO :: $88: 41$. The dorsal interocular groove less than the diameter of the eye, the ventral interocular groove also short. The clypeus is quadrate, truncate in front, its median length slightly more than half its width, the rostrum surpassing two thirds of the postocular dis- 
tance The antennal segments: $1: 2: 3: 4:: 27: 56$ : 130?: $\mathrm{X}($ (ㅇ) $) ; 1: 2: 3: 4:: 25: 58: 135: 65$ (ㅇ).

Pronotum: Length 60 units; pitting indefinite.

Hemelytra: Short, 90 units long, covering the first abdominal segment, surface uneven, veins conspicuous.

Coxae: The distance between the first and second coxae is to that between the second and third as $40: 70$. The anterior and middle acetabula have two pits on each side of the cleft. These are often obscure.

Femora: The anterior femora surpassing the head by half the length of the first antennal segment. The hind femora surpassing the end of the abdomen.

Abdomen: The last abdominal segment of the male without hair tufts. The first genital with hair tufts just laterad of shallow depressions which outline a faint median longitudinal ventral keel. Seen from above, the first genital is broadest at its base, the terminal dorsal process is caudally directed and short, only about one fifth the length of the segment in the male. In the female the terminal process is nearly one third the length of the segment and sharp pointed. The hair tufts on the caudal margin of the last abdominal tergite that are possessed by the females of several species are lacking in this one.

Comparative notes: This new species belongs to the typically African group that includes $H$. ambulator Stål, $H$. albolineolata Reuter, $H$. africana H. \& E., H. trans-

Explanation of Plate 6

Figs. 1-3. Hydrometra poissoni Hungerford. Fig. 1. Dorsal view of last abdominal segments of male. Fig. 2. Lateral view of Jast abdominal segments of male. Fig. 3. Ventral view of last abdominal segments of male.

Figs. 4-8. Hydrometra goodi Hungerford. Fig. 4. Lateral view of last abdominal segments of female. Fig. 5. Lateral view of last abdominal segments of male. Fig. 6. Dorsal view of last abdominal segments of female. Fig. 7. Dorsal view of last abdominal segments of male. Fig. 8. Ventral view of last abdominal segments of male.

(Drawings by Thomasine Neering). 


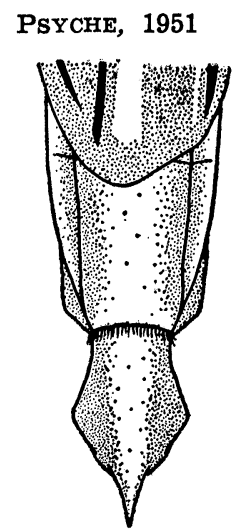

Vol. 58, Plate 6

1 H.poissoni $\sigma^{x}$
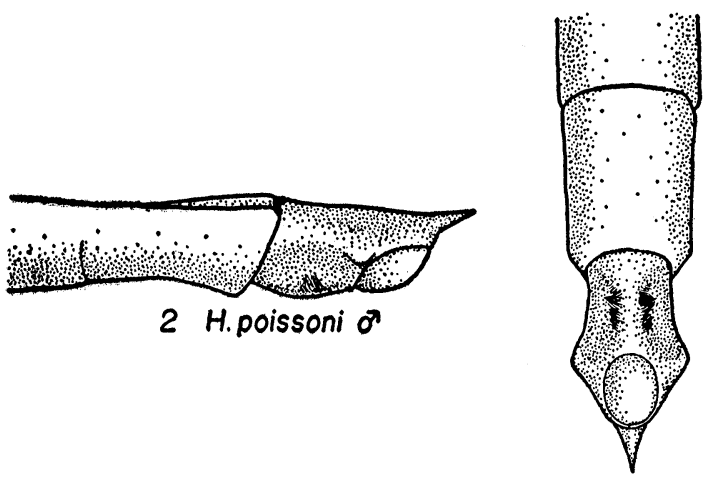

3 H.poissoni o

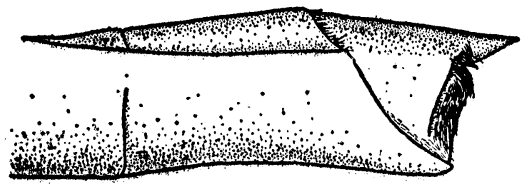

4 H. goodi 우

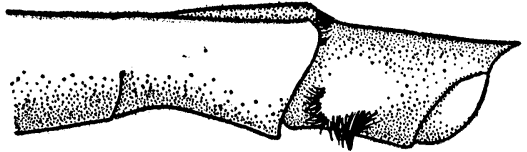

5 H. goodi o

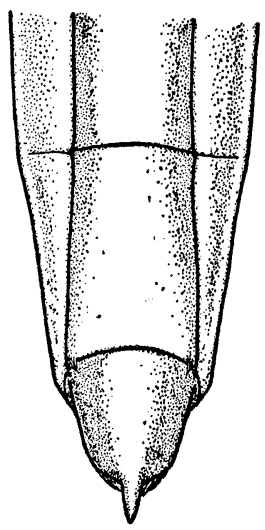

6 H.goodi \&

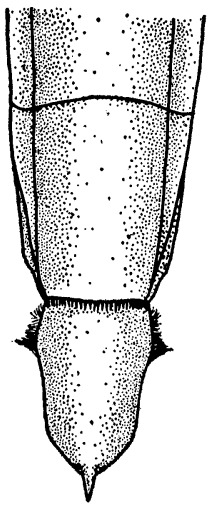

7 H.goodi o

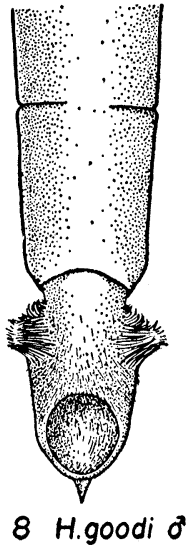

HUNGERFORD - AFRICAN HYDROMETRA 
vaalensis H. \& E., H. ugandae Jacz., H. chopardi Poisson, and $H$. monodi Poisson. It is more slenderly elongate than any of the above. The first antennal segment is relatively longer, plainly surpassing the head by more than half its length. The head itself is more elongate. It may be most nearly related to $H$. ugandae Jaczewski but the females lack the large brush of hairs on the last dorsal abdominal segment that distinguish $H$. ugandae.

Described from one male (holotype) labeled "Sangmelima, Cameroon, W. Africa, Oct. 17, 1934, A. I. Good," a female (allotype) labelled "Sangmelima, Cameroon, 4-16, 1932 , A. I. Good." and two female paratypes, one taken with the holotype and the other with the allotype. These have been in the F. H. Snow Collections under a manuscript name for many years. 

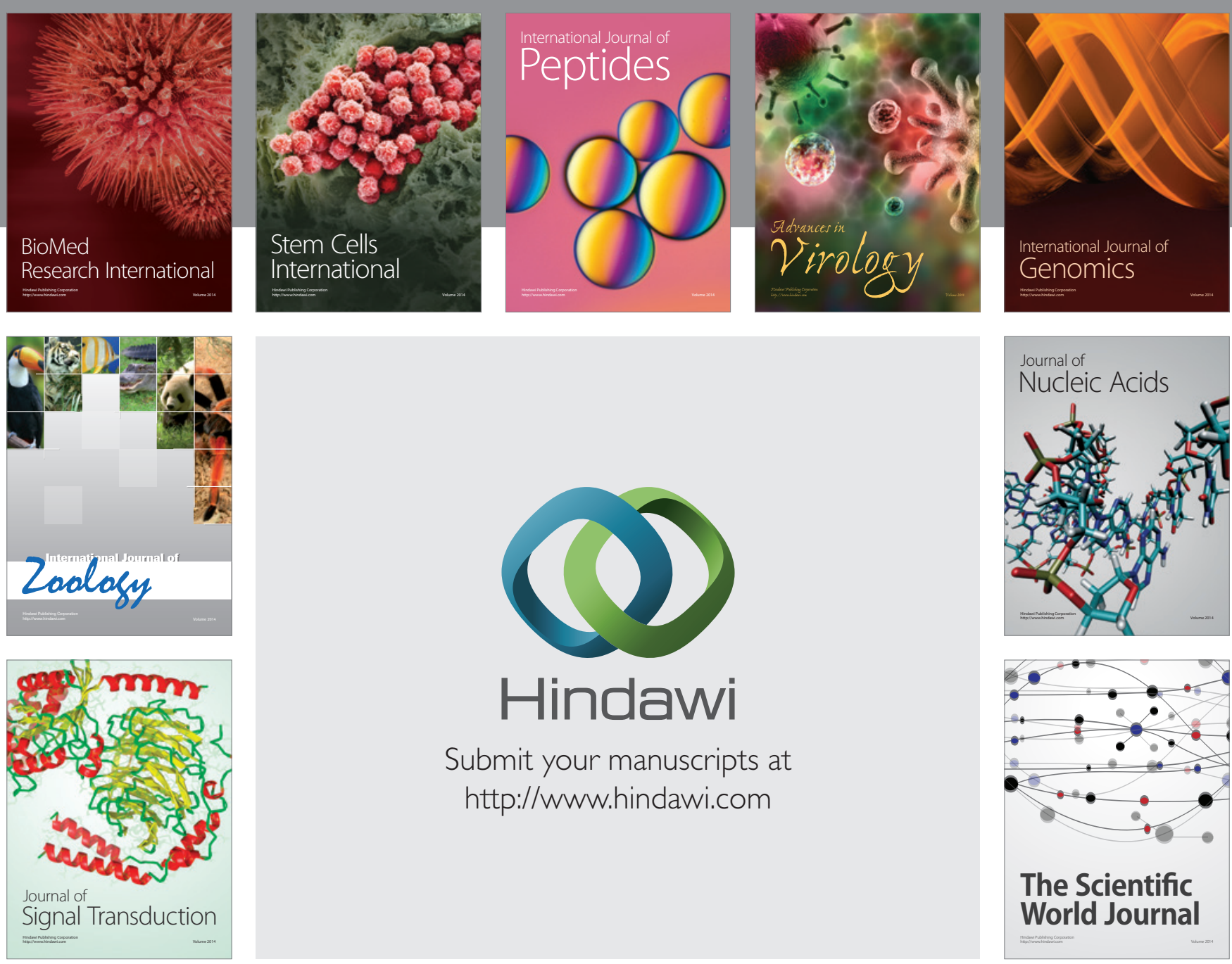

Submit your manuscripts at

http://www.hindawi.com
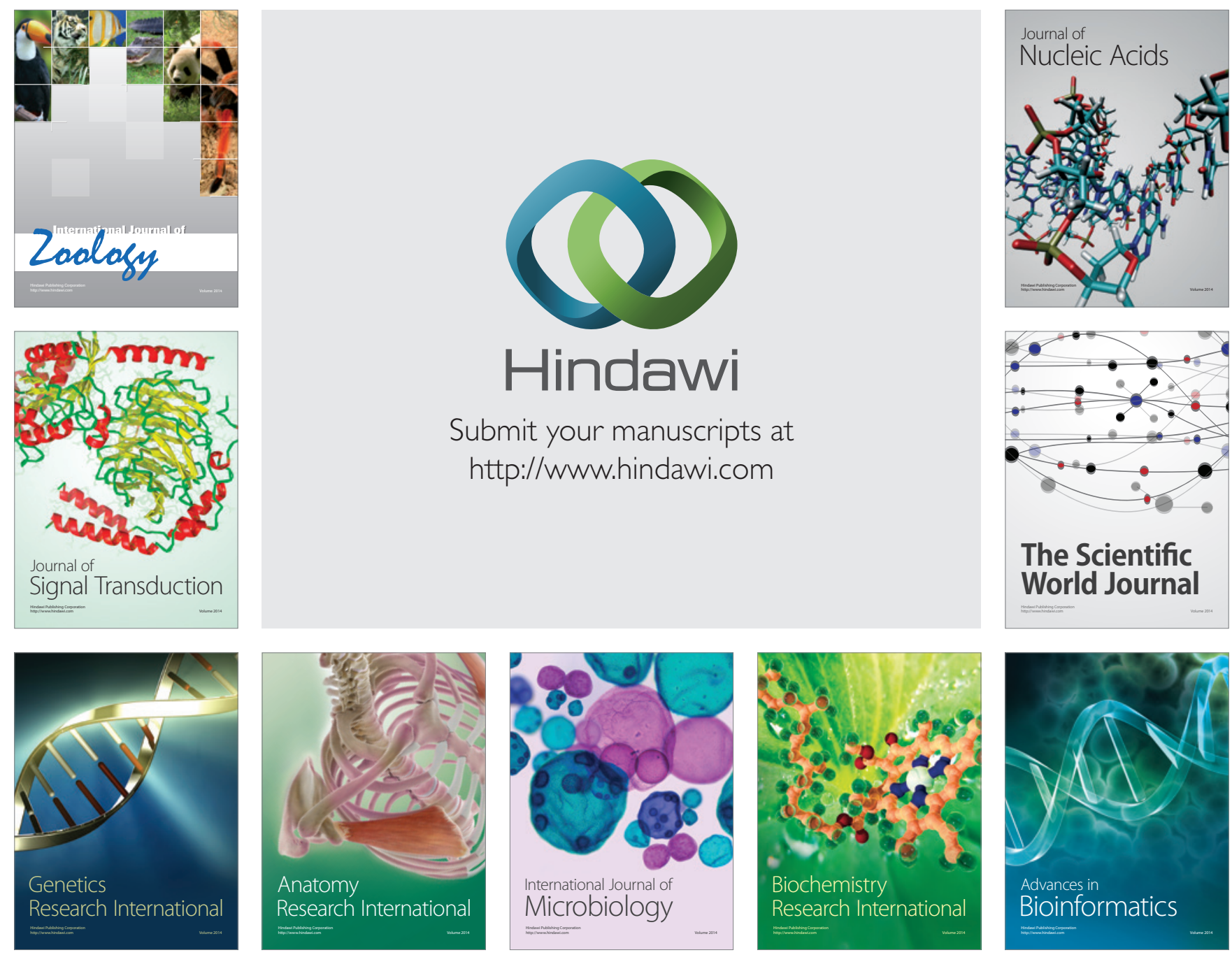

The Scientific World Journal
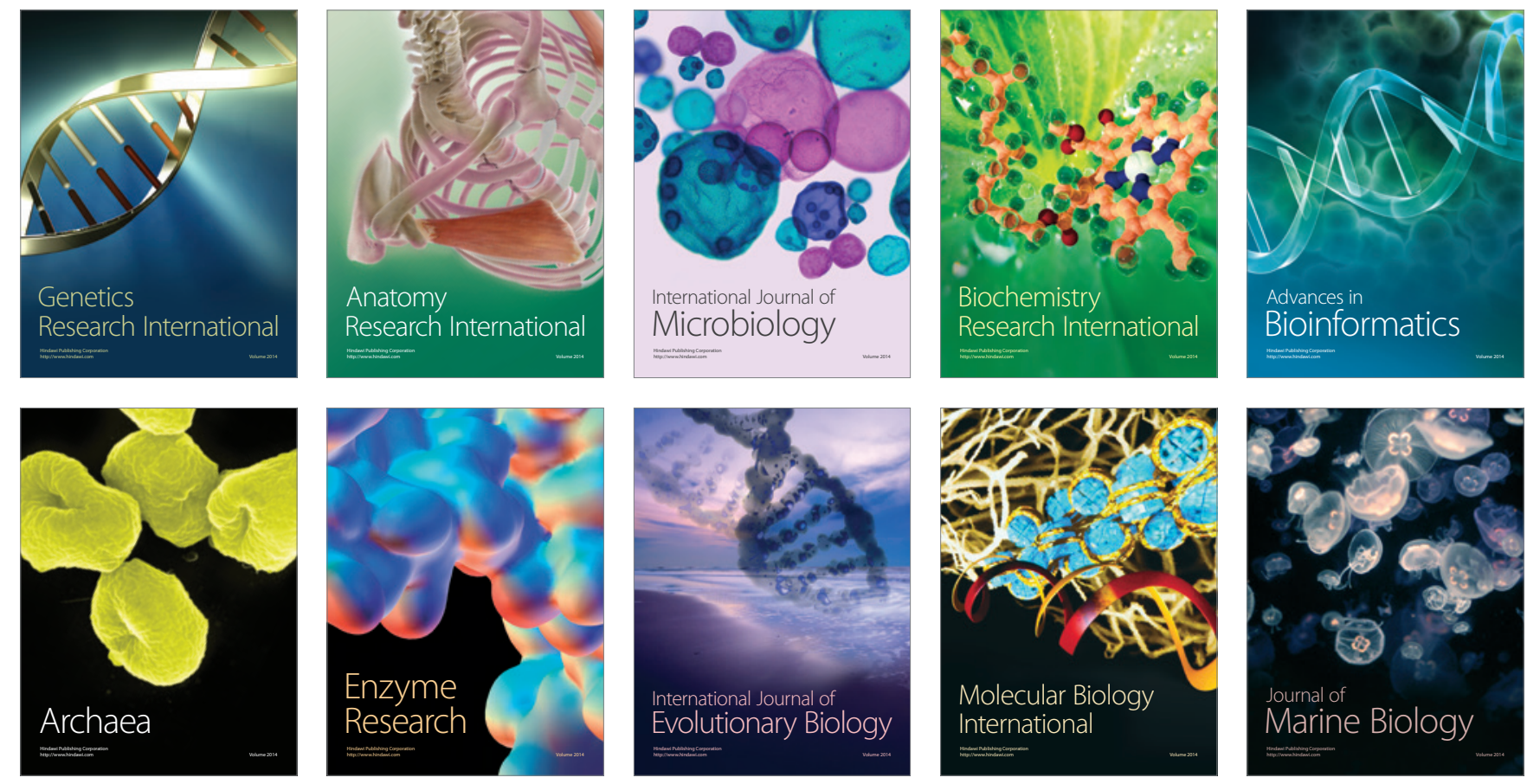